\title{
Aplikasi Business Intelligence Dashboard sebagai Alat Monitoring dan Bahan Pengambilan Keputusan Sales and Account Receivable
}

\author{
Fadil Muhammad Putra, Risna Sari \\ Program Studi Teknik Informatika \\ JurusanTeknik Informatika dan Komputer \\ Politeknik Negeri Jakarta \\ Depok, Indonesia \\ fadilmuhammadputra22@gmail.com, risna.sari@tik.pnj.ac.id
}

Diterima: 10 Maret 2016. Disetujui: 12 April 2016. Dipublikasikan: Mei 2016

\begin{abstract}
Information and data are the important assets for a company. To process data into useful information and getting to be knowledge in the decision making process at management level, there are so many companies which have difficulties, including PT XYZ which was engaging in the production of agricultural materials. PT XYZ had the difficulties in monitoring process and decision-making process related to its main business, sales and account receivable. Business Intelligence dashboard could be the best solution to overcome these problems. This research discusses related design, construction and implementation of business intelligence solutions dashboard starting from the architecture business intelligence, data warehouse in form of a data mart, ETL (extraction, transformation, and loading) process are useful for generating the quality of data, and visualization in the form of dashboard that would represent key business process with $X Y Z$ company. The method used in the development of business intelligence dashboard refers to the six-step method of executive information system that is of the justification, planning, business analysis, design, construction, deployment that would generate digital dashboard for level management. The result is a website application consisting of three digital dashboards that become visualization tools to display the information and knowledge needed in the monitoring process and become material to produce decisions related to sales and receivables. The $B I$ solutions that are developed are in line with expectations and can meet the business needs of PT XYZ.
\end{abstract}

Keywords: business intelligence; dashboard; data warehouse; data mart; executive information system.

\section{PENDAHULUAN}

Perkembangan bisnis yang dinamis mengharuskan perusahaan untuk lebih cepat dan cermat dalam setiap pengambilan keputusan. Tindakan yang keliru dapat menyebabkan kurangnya efektifitas yang berujung pada kerugian yang diterima oleh perusahaan. Dikarenakan pentingnya hal tersebut, banyak perusahaan berlomba-lomba untuk menggali informasi dan knowledge dari data yang dimiliki. Tujuan utamanya adalah untuk mendukung keputusan yang dihasilkan dengan didasari pada hasil analisis informasi dan knowledge yang mewakili keputusan perusahaan.

Dengan berkembang pesatnya teknologi, data yang diperlukan untuk mendukung proses pengambilan keputusan dapat mudah diakses dengan beragam format representasinya. Data tersebut bersifat heterogen yang dapat diolah menjadi informasi hingga knowledge yang dapat digunakan dalam proses pengambilan keputusan baik keputusan yang bersifat operasional maupun strategis. Salah satu metode yang digunakan yakni Business Intelligence (BI).

BI didefinisikan sebagai salah satu metodologi pemanfaatan data untuk menghasilkan informasi hingga menjadi knowledge dalam mendukung pengambilan keputusan strategis. BI sudah banyak diterapkan dalam berbagai jenis sektor industri dan terbukti keberhasilannya. PT XYZ merupakan salah satu Multi National Corporate (MNC) yang sudah mempunyai perusahaan hampir di setiap negara. PT XYZ merupakan perusahaan yang bergerak di bidang farmasi dan pertanian dan sudah mempunyai banyak pelanggan sebagai customer tetap terkait produk-produk yang diproduksi khususnya berkaitan dengan pertanian. Untuk mendukung proses bisnis utama dalam perusahaan, diterapkan ERP SAP yang digunakan secara global bersama dengan beberapa perusahaan di negara lain. Salah satu bisnis utama yang didukung oleh ERP adalah terkait marketing dan sales untuk produk yang diproduksi oleh PT XYZ. Selain itu juga terkait dengan piutang dagang 
(account receivable) dari masing-masing customer.

Pada kasus PT XYZ, saat ini untuk mengolah data dan memvisualisasikan data tersebut masih dilakukan secara manual dengan menggunakan aplikasi Microsoft Excel dan bantuan Pivot Tabel serta dashboard yang dibuat dengan menggunakan fitur Developer pada Microsoft Excel. Berdasarkan hasil wawancara dengan pihak manajemen PT XYZ, terdapat beberapa permasalahan terkait proses tersebut, diantaranya:

1. Data yang diperoleh dari file Microsoft Excel masih berupa data mentah dan memakan waktu untuk proses pengolahan data menjadi informasi.

2. Data yang dapat disimpan dan diolah pada Microsoft Excel terbatas sehingga proses monitoring dan viewhistorical data masih kurang maksimal.

3. Proses monitoring sales cukup membutuhkan waktu yang lama untuk bisa sampai ke pihak manajemen.

PT XYZ membutuhkan aplikasi BI yang menyediakan informasi monitoring terkait sales dan account receivable pada customer untuk meningkatkan efektifitas dan efisiensi manajemen dalam pengambilan keputusan strategis. Maka dari itu, pengembangan aplikasi BI sebagai solusi untuk membantu manajer dalam melakukan pemantauan proses bisnis, khususnya terkait sales and account receiveable. Pengembangan meliputi data mart sebagai database yang terintegrasi dan dashboard sebagai alat visualisasi dalam bentuk grafis.

\section{TINJAUAN PUSTAKA}

\section{A. Business Intelligence (BI)}

BI dikategorikan secara luas sebagai aplikasi dan teknologi untuk mengumpulkan, menyimpan, menganalisis dan menyediakan akses ke data untuk membantu perusahaan dalam membuat keputusan bisnis yang lebih baik. Aplikasi BI meliputi kegiatan sistem pendukung keputusan, query dan pelaporan, online analytical processing (OLAP), analisis statistik, peramalan (forecasting), dan data mining. [1]Tujuan utama dari sistem BI adalah untuk menyediakan knowledge yang digunakan para pengambil keputusan di berbagai level dalam mengambil keputusan agar lebih efektif dan di waktu yang tepat (timely decision) agar dapat sukses dan bertahan di dunia bisnis [2]. Daur hidup (life cycle) proyek EIS (Executive Information System) atau dikenal dengan BI mengacu pada 6 tahapan yang terdapat dalam Gambar 1.

\section{B. Data Warehouse}

Istilah data warehouse mengacu pada pengelolaan data besar. Fungsi data warehouse adalah untuk keperluan reporting dan analisis. Bersifat numerik dan dioperasikan secara agregat. Data tersimpan secara terstruktur dalam bentuk starschema yang berbeda dengan struktur database transaksional. Perbedaan antara data operasional dan data warehouse dapat dilihat pada Tabel 1.[2]

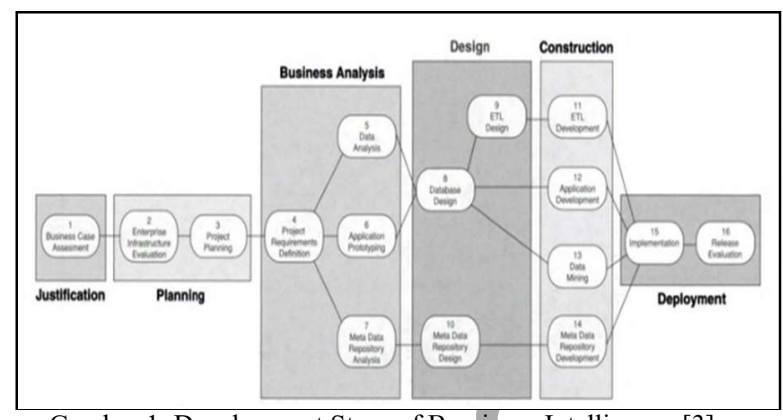

Gambar 1. Development Steps of Bussiness Intelligence [3]

\section{B. Data Warehouse}

Istilah data warehouse mengacu pada pengelolaan data besar. Fungsi data warehouse adalah untuk keperluan reporting dan analisis. Bersifat numerik dan dioperasikan secara agregat. Data tersimpan secara terstruktur dalam bentuk starschema yang berbeda dengan struktur database transaksional. Perbedaan antara data operasional dan data warehouse dapat dilihat pada Tabel 1.[2]

Salah satu tahap terpenting dalam BI adalah tercapainya kualitas terbaik data. Proses pengumpulan dan pemrosesan data menjadi informasi untuk kebutuhan BI disebut ETL (extraction, transformation, dan loading).

Dalam membangun multidimensionaldata warehouse, data dari berbagai sumber (data operasional, ERP, dan excel) perlu dilakukan proses ekstraksi dan diletakkan pada lingkungan BI. Kunci tahapan ini adalah konektivitas antar sumber data. Setelah data dari berbagai sumber tersebut diekstraksi, maka akan masuk ke tahapan selanjutnya.

Tahap transformasi adalah tahap yang paling luas dan lama. Tahap ini tergolong kompleks karena mencakup seluruh aktivitas untuk membuat data sesuai dengan model multidimensional yang membentuk data warehouse. Database terpisah dari data warehouse disediakan untuk menampung hasil tahap transformasi ini. Penyimpanan sementara ini disebut staging/work area. Setelah seluruh tahap transformasi berjalan, maka data siap untuk ditampilkan (load) ke dalam modelmultidimensional.

Tahap loading adalah tahap pemuatan setelah melalui tahap ekstraksi dan transformasi. Tahap ini membutuhkan perhatian lebih karena data yang ditampilkan (load) langsung dirilis dan dilihat oleh pengguna sistem (pihak manajemen).

\section{Data Mart}

Data warehouse pada dasarnya mengandung data dari berbagai sumber dan meliputi subyek yang luas dan banyak. Sedangkan data mart lebih spesifik secara subyek dan mengandung subset dari data warehouse yang digunakan di dalam perusahaan. Data Mart adalah tempat end user secara langsung 
mengakses dan mengawasi proses analisis data. [4] Data mart terbentuk dari satu pengguna yang mempunyai ekspektasi umum untuk data yang harus dilihat dan seringkali dikelompokkan berdasarkan pengguna dan departemennya. Sebuah data warehouse dapat terdiri dari satu atau lebih data mart. Tujuan dari data mart adalah untuk menganalisis maupun mengimplementasikan aplikasi decision support pada fungsi spesifik. Data mart bersifat subset data dari data warehouse dan biasanya terintegrasi dengan data lain yang masih berhubungan dengan data mart tersebut. Contoh data penjualan (sales) mempunyai informasi tambahan terkait hal lain seperti informasi product dan customer. Data penjualan tersebut bersifat subyektif. [5]

\begin{tabular}{|c|c|}
\hline OPERATIONAL DATA & $\begin{array}{c}\text { DATA } \\
\text { WAREHOUSE }\end{array}$ \\
\hline Application oriented & Subject oriented \\
\hline Detailed & $\begin{array}{l}\text { Summarized, } \\
\text { otherwise refined }\end{array}$ \\
\hline $\begin{array}{l}\text { Accurate, as of the moment of } \\
\text { access }\end{array}$ & $\begin{array}{l}\text { Represents values over time } \\
\text { snapshots }\end{array}$ \\
\hline Serves the clerical community & $\begin{array}{l}\text { Serves the managerial } \\
\text { community }\end{array}$ \\
\hline Can be updated & Is not updated \\
\hline $\begin{array}{l}\text { Run repetitively and non } \\
\text { reflectively }\end{array}$ & Run heuristically \\
\hline $\begin{array}{l}\text { Requirement for processing } \\
\text { understood before initial } \\
\text { development }\end{array}$ & $\begin{array}{l}\text { Requirement for } \\
\text { processing not completely } \\
\text { understood before } \\
\text { development }\end{array}$ \\
\hline $\begin{array}{l}\text { Compatible with the software } \\
\text { development life cycle }\end{array}$ & $\begin{array}{l}\text { Completely different in } \\
\text { life cycle }\end{array}$ \\
\hline Performance sensitive & Performance relaxed \\
\hline Accessed a unit at a time & Accessed a set at a time \\
\hline Transaction driven & Analysis driven \\
\hline $\begin{array}{l}\text { Control of update a major } \\
\text { concern in term of ownership }\end{array}$ & Control of update no issue \\
\hline High availability & Relaxed availability \\
\hline Managed in its entirety & Managed by subsets \\
\hline Nonredundancy & Redundancy is fact of life \\
\hline Static structure; variable contents & Flexible structure \\
\hline $\begin{array}{l}\text { Small amount of data used in a } \\
\text { process }\end{array}$ & $\begin{array}{l}\text { Large amount of data } \\
\text { used in a process }\end{array}$ \\
\hline
\end{tabular}

\section{Database Scheme}

Perancangan dimensional untuk database relasional disebut star schema. Skema ini terdiri dari dua buah tabel, yaitu tabel dimensi dan tabel fakta. Dimensi yang berhubungan dikelompokkan sebagai kolom dalam tabel dimensi, dan fakta-fakta disimpan sebagai kolom dalam tabel fakta.

Tabel dimensi adalah tabel yang menyediakan deskripsi bagi tabel fakta dan menjelaskan siapa, apa, kapan, dimana dan bagaimana pengukuran pada tabel fakta. Terdiri dari beberapa atribut/kolom yang lebih sedikit dibanding tabel transaksi. Fungsi umum dari tabel dimensi yaitu menyaring query atau menampilkan (select) data. Tabel fakta adalah hasil gabungan tabel dimensi dengan perhitungan tertentu.

Contohnya ketika akan mengetahui jumlah penjualan satu customer, berdasarkan produk, bulan dan tahun. Tabel fakta dapat berisi ratusan ribu bahkan miliyaran baris. Oleh karena itu, diperlukan normalisasi untuk menjadikan tabel tersebut efisien. Gambar 2, contoh star schema, berdasarkan faktafakta dan dimensi untuk proses order.

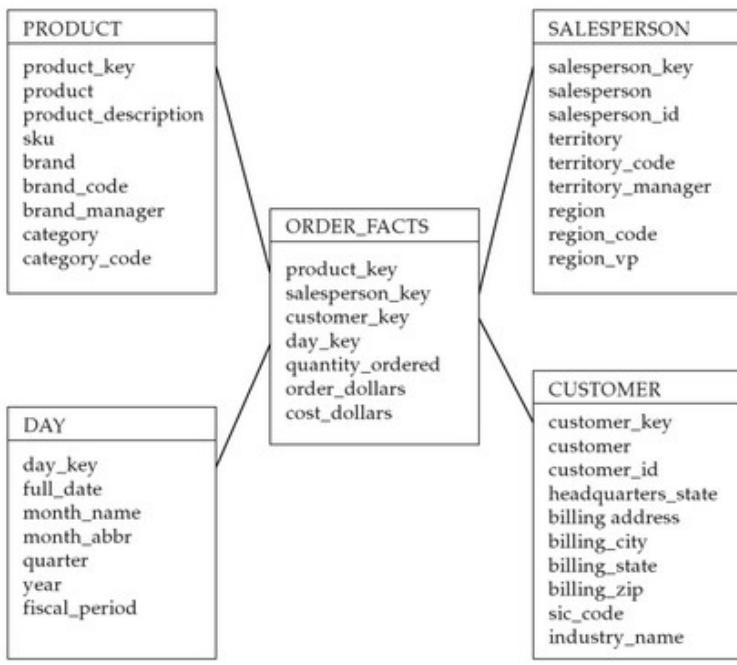

Gambar 2. Sample Star Scheme Order Process [3]

E. Komponen Visual

Komponen visualisasi yang akan dijelaskan terdiri dari 2 hal, yaitu Online Analytical Processing (OLAP) dan dashboard.

OLAP adalah teknologi aplikasi yang tujuannya mengumpulkan, mengatur, memproses, dan menampilkan data dimensional yang dibutuhkan untuk analisis oleh pihak manajemen. Model OLAP mempunyai karakteristik yang memungkinkan user menulis formula sederhana untuk proses analisis yang keluarannya berupadimensi. Salah satu kelebihan OLAP adalah real time data berbeda dengan report biasanya. Report berdasarkan analisis ini dijadikan grafik yang dapat memudahkan pengguna sistem business intelligence mempelajari dan membuat analisis dan keputusan. Perbedaan OLTP dan OLAP dapat dilihat pada Tabel 2

TABEL 2. PERBEDAAN OLTP DAN OLAP [2]

\begin{tabular}{|c|c|c|}
\hline & OLTP & OLAP \\
\hline Users & $\begin{array}{ll}\text { Clerk, } & I T \\
\text { professional }\end{array}$ & $\begin{array}{l}\text { Knowledge } \\
\text { worker }\end{array}$ \\
\hline \multirow{2}{*}{$\begin{array}{l}\text { Function } \\
\text { DB } \\
\text { Design }\end{array}$} & Day to day operations & Decision support \\
\hline & Application-oriented & Subject-oriented \\
\hline Data & $\begin{array}{l}\text { Current up } \\
\text { detailed, flat relational } \\
\text { isolated }\end{array}$ & $\begin{array}{l}\text { Historical, } \\
\text { Summarized, } \\
\text { Mutlidimensional, } \\
\text { Integrated, } \\
\text { Consolidated }\end{array}$ \\
\hline \multirow{2}{*}{$\begin{array}{l}\text { Usage } \\
\text { Access }\end{array}$} & Repetitive & Ad-hoc \\
\hline & $\begin{array}{l}\text { Read/write, index/has on } \\
\text { primary key }\end{array}$ & $\begin{array}{l}\text { Lots } \quad \text { of } \\
\text { scans }\end{array}$ \\
\hline $\begin{array}{l}\text { Unit of } \\
\text { work }\end{array}$ & $\begin{array}{l}\text { Short, } \\
\text { transaction }\end{array}$ & $\begin{array}{l}\text { Complex } \\
\text { query }\end{array}$ \\
\hline
\end{tabular}


Aplikasi Business Intelligence Dashboard sebagai Alat Monitoring dan Bahan Pengambilan Keputusan Sales and Account Receivable

\begin{tabular}{|l|l|l|}
\hline $\begin{array}{l}\text { \# records } \\
\text { accessed }\end{array}$ & Tens & Millions \\
\hline \# users & Thousands & Hunderds \\
\hline DB size & 100MB-GB & 100 GB-TB \\
\hline Metric & $\begin{array}{l}\text { Transaction } \\
\text { throughput }\end{array}$ & $\begin{array}{l}\text { Query throughput, } \\
\text { response }\end{array}$ \\
\hline
\end{tabular}

Dashboard adalah alat visualisasi dalam business intelligence sebagai aplikasi yang berhubungan langsung dengan pengguna akhir (end user). Menurut Eckerson [6], dashboard adalah aplikasi multi layer dalam Business Intelligence dan infrastruktur integrasi data yang memungkinkan perusahaan dan organisasi untuk mengukur, melakukan monitoring, dan mengatur perfoma bisnis dengan lebih efektif. Definisi tersebut menjelaskan bahwa dashboard bukan hanya sekadar layar dengan grafik-grafik. Terdapat tiga buah tipe dashboard, yaitu operational, tactical dan strategic.

Operational Dashboard berfungsi untuk memonitor inti proses operasional dan akan digunakan terutama untuk pekerja yang berada di garis terdepan (staff) dan (supervisor) yang bersinggungan langsung dengan pelanggan atau mengatur pembuatan/pengiriman produk dan jasa perusahaan. Utamanya menyampaikan informasi lengkap, bukan berupa simpulan. Menekankan pada monitoring bukan analisis atau management.

Tactical Dashboard ferfungsi untuk melakukan proses tracking dan proyek departemental yang menarik bagi segmen organisasi tertentu, yaitu tingkat manajemen. Manajer dan business analyst memakai dashboard tipe ini untuk membandingkan perfoma dari setiap area proyek, rencana anggaran, forecasts, atau hasil pada periode sebelumnya. Tipe ini menekankan pada analisis dibanding dengan monitoring dan management.

Strategic Dashboard berfungsi memonitor eksekusi-eksekusi pencapaian objektif dan goals perusahaan dan secara teratur dengan implementasi menggunakan pendekatan Balance Scorecards. Tujuan tipe dashboard ini untuk menyelaraskan tujuan perusahaan pada tiap departemen. Tipe ini menekankan pada manajemen dibanding monitoring dan analisis. Perbedaan 3 buah tipe dashboard di atas dapat dilihat pada Tabel 3.

Penjualan (sales) merupakan sebuah proses di mana kebutuhan pembeli dan penjual dipenuhi, melalui pertukaran informasi dan kepentingan. Di dalam suatu organisasi, departemen atau fungsi yang menghasilkan pendapatan atau uang adalah departemen penjualan (sales department). Tim penjualan ini yang berhubungan dengan pelanggan (customer). Pendapatan perusahaan sangat ditentukan oleh besar kecilnya penjualan. Kegiatan penjualan sendiri berhubungan dengan kegiatan pemasaran (marketing).
TABEL 3. TIPE DASHBOARD [6]

\begin{tabular}{|c|c|c|c|}
\hline Operational & Tactical & Strategical \\
\hline Purpose & $\begin{array}{c}\text { Monitor } \\
\text { Operations }\end{array}$ & $\begin{array}{c}\text { Measures } \\
\text { progress }\end{array}$ & Execute strategy \\
\hline Scope & $\begin{array}{c}\text { Supervisors, } \\
\text { specialists }\end{array}$ & $\begin{array}{c}\text { Managers, } \\
\text { Analysts }\end{array}$ & $\begin{array}{c}\text { Executives, } \\
\text { managers, staff }\end{array}$ \\
\hline Information & Detailed & $\begin{array}{c}\text { Detailed/ } \\
\text { summary }\end{array}$ & $\begin{array}{c}\text { Detailed/ } \\
\text { Summary }\end{array}$ \\
\hline Updates & Intra-day & Daily/weekly & $\begin{array}{c}\text { Monthly/ } \\
\text { quarterly }\end{array}$ \\
\hline Emphasis & Monitoring & Analysis & Management \\
\hline
\end{tabular}

Menurut Jonathan Reuvid [7] perbedaan mendasar dari marketing dan sales adalah marketing termasuk ke dalam consumer research (untuk mengidentifikasi kebutuhan customer) dan mengiklankan produk/jasa untuk menaikkan kesadaran dan membangun brand.Tujuan khusus dari marketing adalah menghasilkan kepentingan dalam produk/jasa dan menciptakan peluang. Di samping itu, kegiatan sales berfokus pada bagaimana mengkonversikan prospek untuk pelanggan yang melakukan pembayaran. Penjualan melibatkan interaksi secara langsung dengan melakukan prospek untuk membujuk mereka agar membeli produk atau jasa.

\begin{tabular}{|c|c|c|c|c|r|r|}
\hline \multicolumn{7}{|c|}{$\begin{array}{c}\text { Jeffry Haber Company } \\
\text { Accounts Receivable Aging } \\
\text { As of December 31, 2002 }\end{array}$} \\
\hline Customer & Total & Current & $\mathbf{3 1 - 6 0}$ & $\mathbf{6 1 - 9 0}$ & $\mathbf{9 1 - 1 2 0}$ & $\mathbf{1 2 0 +}$ \\
\hline ABC Comp & $2,000.00$ & 500.00 & 500.00 & 500.00 & 500.00 & \\
\hline DEF Comp & $5,500.00$ & & & $3,000.00$ & $1,000.00$ & $1,500.00$ \\
\hline GHI Comp & $2,400.00$ & $2,400.00$ & & & & \\
\hline Total & $9,900.00$ & $2,900.00$ & 500.00 & $3,500.00$ & $1,500.00$ & $1,500.00$ \\
\hline Allowance \% & & & $1 \%$ & $5 \%$ & $10 \%$ \\
Allowance & 260.00 & & & 35.00 & 75.00 & 150.00 \\
\hline
\end{tabular}

Gambar 3. Performance Sales Monitoring Architecture [8]

\section{F. Piutang (account receivable)}

Ketika barang atau jasa yang dijual, perusahaan menerima uang tunai atau janji pembayaran di masa depan. Sebuah penjualan kredit menghasilkan piutang (account receivable) yang mewakili uang yang dimiliki perusahaan. Account Receivable merupakan rekening yang timbul dari penjualan kredit yang belum dikumpulkan. Piutang dagang timbul akibat adanya penjualan secara kredit agar dapat lebih banyak menjual produk barang dan jasa. Istilah piutang meliputi semua klaim dalam bentuk uang terhadap entitas lainnya, termasuk individu, perusahaan atau organisasi lainnya. Dalam kegiatan perusahaan yang normal, biasanya piutang akan dilunasi dalam jangka waktu kurang dari satu tahun sehingga digolongkan dalam aktiva lancar.

Piutang adalah salah satu sumber kehidupan untuk sebuah perusahaan, oleh karena itu pengendalian internal piutang adalah hal mutlak yang harus dilakukan. Pengendalian internal 
bertujuan untuk meningkatkan efektivitas dan efisiensi perusahaan di mata pelanggannya. Alih-alih memperkirakan beban utang berdasarkan penjualan, perusahaan lebih menggunakan laporan yang disebut Account Receivable Aging. Rincian dari piutang terkait berapa banyak yang harus dibayarkan oleh setiap pelanggan dan berapa lama jumlah yang telah berutang. Dengan kata lain, Account Receivable Aging (AR Aging) merupakan metode untuk mengidentifikasi berapa lama rekening yang sudah/ akan jatuh tempo. Ini berarti bahwa rekening lewat jatuh tempo diidentifikasi sesuai dengan lamanya waktu yang telah dibayarkan. Dalam beberapa tahun terakhir, sebagian perusahaan mulai berfokus tentang memantau piutang pelanggannya dengan menggunakan laporan jadwal piutang dagang (account receivable aging schedule). Kolom khusus untuk laporan tersebut adalah current, 31-60 days, 61-90 days, 91-120 days, dan 120 +days.

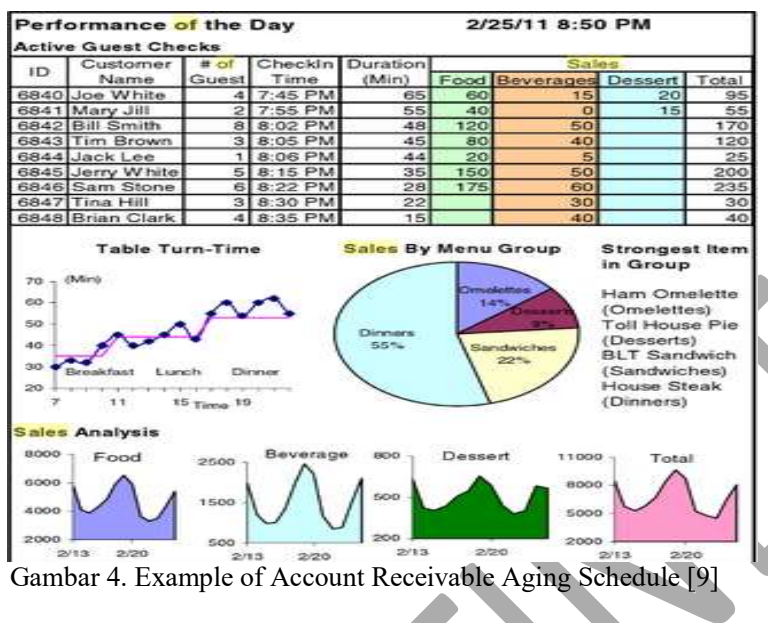

\section{ANALISA DAN PERANCANGAN}

\section{A. Business Analysis}

Daftar kebutuhan fungsional (Functional Requirements) adalah sebagai berikut:

1) Fungsi ETL: dimulai dari proses upload transactional data by user kemudian transactional data tersimpan ke dalam data warehouse dan dilakukan proses extract, transform kemudian proses load data ke dalam data mart yang sudah dirancang dan dibuat.

2) Fungsi Management Master Data: adalah proses pengelolaan data master yaitu data customer, material product, dan remarks (remarks by distributor dan remarks by area). Di dalamnya terdapat fungsi CRUD (create, retrieve, update dan delete) serta upload data untuk remarks.

3) Fungsi Management User Data: melakukan proses manajemen data user yaitu data user admin, admin area. Di dalamnya terdapat fungsi CRUD (create, retrieve, update dan delete).

4) Fungsi Visualisasi : Dashboard

a) Menampilkan historical analysis data top 15 actual sales, last year sales, budget and forecasting by product in month, year pada national, area, or customer.

b) Menampilkan historical analysis data top 15 sales by product in year to date pada national, area, or customer.

c) Menampilkan contribution in percentage top 15 actual sales by product in month, year national, area, or customer dalam bentuk pie chart.

d) Menampilkan sales by group in month, yearatau in year to date pada national, area, or customer dalam bentuk bar chart.

e) Menampilkan time series of sales by product in period to date pada national, area, or customer dalam bentuk line chart.

f) Menampilkan account receivable aging (current $A R$, overdue $A R$, longoverdue AR) in month, year pada national, area, or customer dalam bentuk bar chart.

g) Menampilkan sales vs account receivable vs inventory vs payment in period to date pada national, area, or customer dalam bentuk line chart dan bar chart.

h) Menampilkan table historical data sales, account receivable (current, overdue, long overdue), inventory, payment in period to date pada national, area, or customer.

i) Menampilkan pivot table Account Receivable Aging (amount, current, overdue, long overdue, credit limit) in month, year pada national, area or customer.

j) Menampilkan historical analysis data actual sales, last year sales dan forecasting by area in month, year pada group or brand.

k) Menampilkan historical analysis data actual sales, last year sales dan forecasting by area in in year to date pada group or brand.

1) Menampilkan contribution in percentage actual sales, by area in month, year, group, brand dalam bentukpie chart.

m) Menampilkan time series of sales by area by crop type in period to date pada group, or brand dalam bentuk line chart.

Daftar kebutuhan non-fungsional (Non-Functional Requirements) adalah sebagai berikut:

$\checkmark$ Perfomance Response time, sistem dapat memberikan respon kepada user kurang dari satu menit.

$\checkmark$ Tampilan Antar Muka

$\checkmark$ Sistem menggunakan grafik yang interaktif, Sistem menampilkan grafik dengan warna yang sesuai dengan template perusahaan PT XYZ

$\checkmark$ Security: sistem hanya dapat diakses oleh pihak yang berkepentingan seperti pihak manajemen (BPA, ASM, Crop Manager) dan beberapa pihak yang terlibat di dalam proses pengambilan keputusan dalam perusahaan. 
B. Desain

Sebelum melakukan implementasi, dilakukan perancangan BI yang meliputi desain arsitektur serta perancangan ETL dan star scheme.

1) Arsitektur BI

Secara umum BI memiliki arsitektur yang hampir serupa. Perbedaan biasanya terjadi pada jenis dari sumber data dan jenis dari database yang akan menjadi tempat penyimpanan hasil pengolahan data. Arsitektur BI yang akan diimplementasikan PT XYZ dapat dilihat pada Gambar 5.

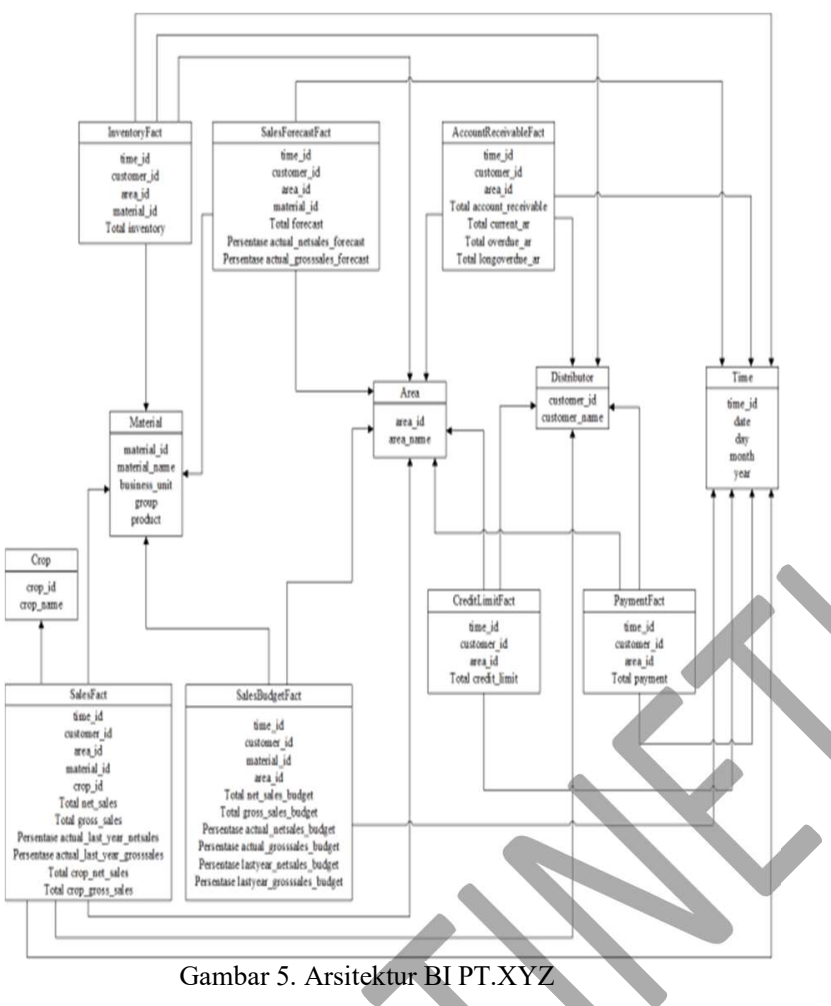

2) Perancangan ETL dan Star Scheme

Indikator total net sales, total gross sales, persentase actual-last year net sales, persentase actual-last year gross sales, dan total crop net sales, total crop gross sales dibuat dalam satu star schema karena memiliki dimensi yang merepresentasikan nilai pada tabel yang sama. Hal yang sama juga dilakukan pada indikator total account receivable, total current ar, total overdue ar, total long overdue ar. Keseluruhan starschema dapat dilihat pada Gambar 6. Star Schema ini yang akan menjadi dasar dalam membuat ETL tools pada proses construction.

Proses ETL diperlukan untuk mengubah tingkat ketelitian data, melakukan agregasi dan mengubah model data menjadi yang multidimensional karena tingkat ketelitian dari data yang diunggah tersebut masih sangat tinggi karena berasal dari data transaksi. Salah satu proses ETL dapat dilihat pada Gambar 7.
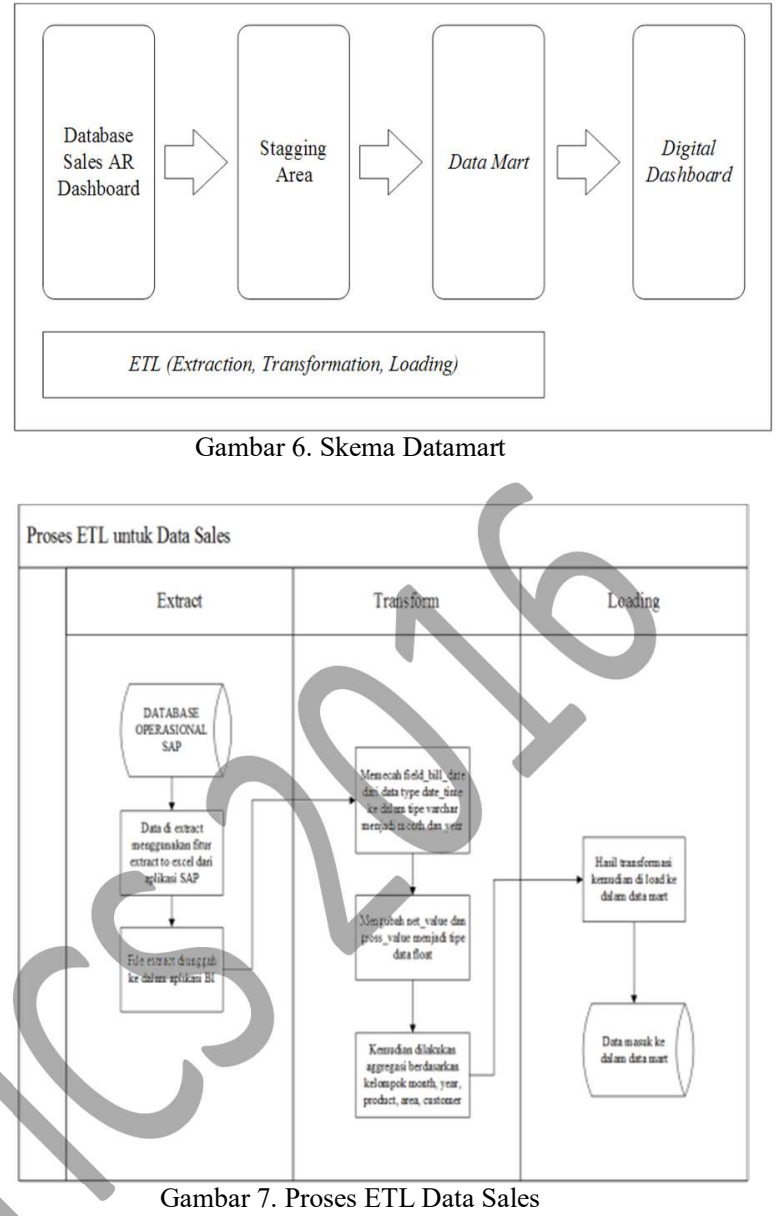

Tampilan data setelah melalui proses ETL dan dilakukan join dengan tabel dimensi dapat dilihat pada Gambar 8.

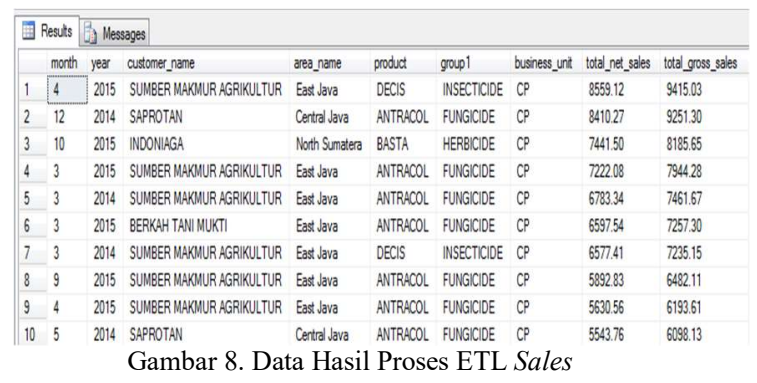

\section{IMPLEMENTASI DAN PENGUJIAN SISTEM}

\section{A. Implementasi Antarmuka}

Halaman dashboard sales pada Gambar 9 menampilkan informasi terkait sales by product dari PT XYZ. Dashboard ini terdiri dari lima bagian, yakni historical data terkait trend analisis sales by product top 15 in month to date, historical data terkait trend analisis sales by product top 15 in year to date, grafik sales percentage contribution top 15 product in month to date, grafik sales by group in month to date atau in year to date dan grafik trend analysis time series vs gross sales by product.[10] 


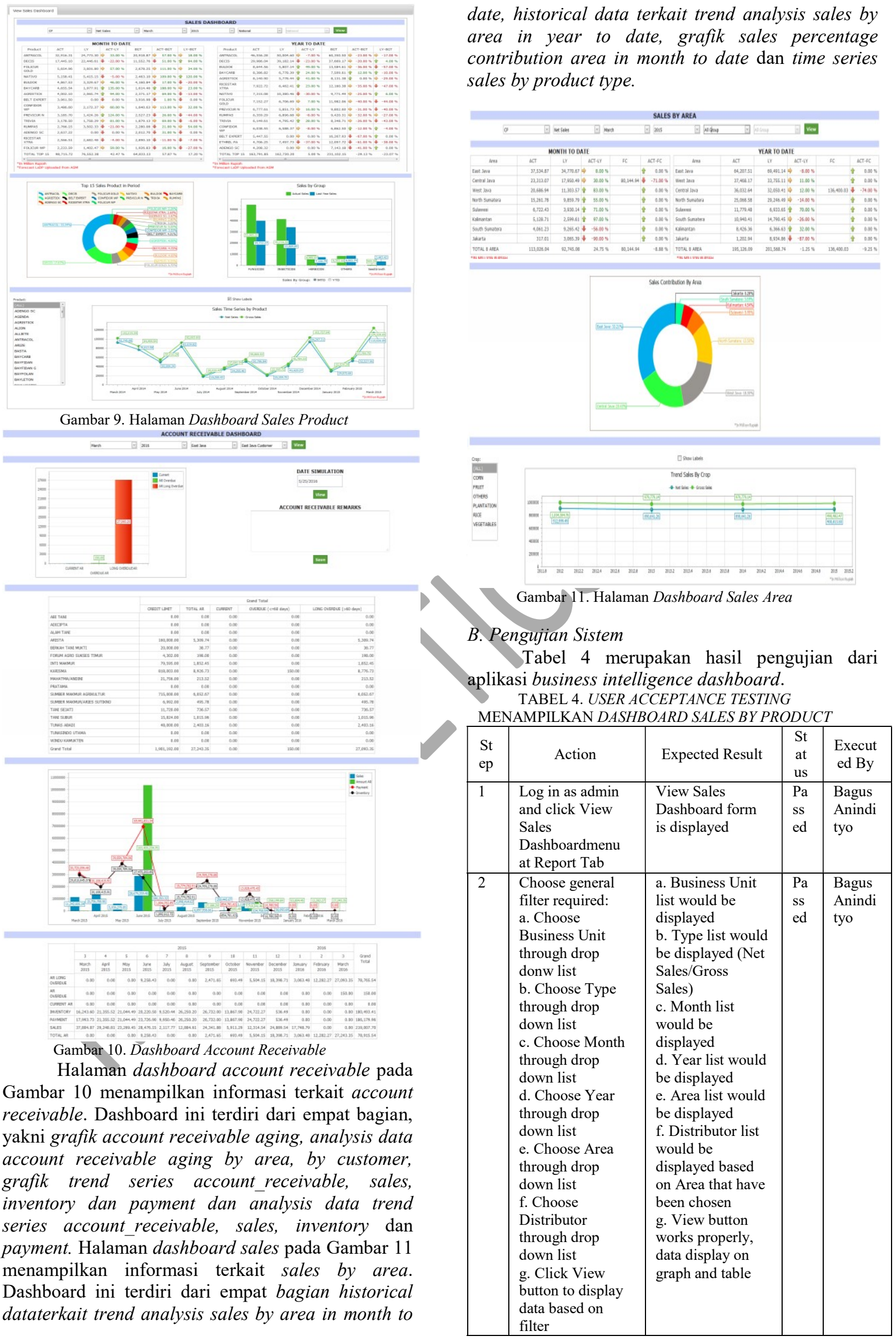




\section{KESIMPULAN}

Setelah semua tahapan metodologi penelitian dilakukan, didapatkan simpulan bahwa proses pengembangan Business Intelligence pada PT XYZ telah dijalankan dari tahap pertama hingga tahap terakhir sesuai dengan enam tahapan metode pengembangan aplikasi BI. Selain itu, solusi BI yang dihasilkan merupakan aplikasi berbasis website yang terdiri dari tiga buah digital dashboard yang menjadi alat visualisasi untuk menampilkan informasi dan knowledge yang diperlukan dalam proses monitoring dan menjadi bahan pengambilan keputusan strategis terkait sales dan account receivable pada PT XYZ. Hasil evaluasi terkait pengembangan Business Intelligence Dashboard Application yang dilakukan menunjukkan bahwa solusi BI yang dikembangkan sudah sesuai dengan ekspektasi serta dapat memenuhi kebutuhan bisnis dari PT XYZ.

\section{REFERENSI}

[1] Brijs, B., "Business Analysis for Business Intelligence". United States of America. 2013

[2] Vercellis, C., "Data Mining and Optimization for Decision Making". A John Wiley and Sons, Ltd. 2009.

[3] Larissa T. Moss, S. Atre, "Business Intelligence Roadmap: The Complete Project Lifecycle for Decision-Support Applications". Addison-Wesley. 2003

[4] Chris J. N.,"Sales Management. Taylor \& Francis". 2010

[5] Rajiv Sabherwal, I. B.-F.., Business Intelligence: Practices, Technologies, and Management. United States of America: John Willey \& Sons, Inc. 2012

[6] Eckerson, W. W.,Performance Dashboards: Measuring, Monitoring, and Managing Your Business, 2nd Edition. Wiley. 2010

[7] Reuvid, J.,Managing Business Risk: A Practical Guide to Protecting Your Business. United States: Kogan Page Limited. 2014

[8] Stefanie R., Farouk T., Karsten W., Business Process Management: 9th International Conference, BPM 2011. Springer. 2011

[9] Harber R, Jeffry.,'Accounting Demystified American Management Association. NewYork 2004

[10] Sherman, R., Business Intelligence Guidebook: From Data Integration to Analytics. Amsterdam: Elsevier Inc. 2014 